\title{
Histometría de la glándula sublingual de ratones (Mus musculus) machos y hembras infectados con la cepa RAL del parásito de Chagas, Trypanosoma cruzi
}

\author{
Sérgio de Albuquerque ${ }^{1}$, Ruberval Armando Lopes ${ }^{2,3}$, Miguel Angel Sala ${ }^{3}$, Ana Amélia Carraro \\ Abrahão $^{1}$ \& Rosa Domingues Ribeiro ${ }^{1,2}$ \\ 1. Departamento de Análisis Clínicos y Bromatológicos, Facultad de Ciencias Farmacéuticas de Ribeirão Preto, USP, \\ Brasil. \\ 2. Universidad de Franca, Franca, SP, Brasil. \\ 3. Departamento de Morfología, Estomatología y Fisiología, Facultad de Odontología de Ribeirão Preto, Universidad de \\ São Paulo, Avenida do Café s/n, CEP 14040-904, Ribeirão Preto, SP, Brasil; ruberlopes@yahoo.com.br
}

Recibido 26-II-2007. Corregido 15-XI-2007. Aceptado 01-IV-2008.

\begin{abstract}
Histometry of the sublingual gland in male and female mice (Mus musculus) infected with the RAL strain of the Chagas parasite, Trypanosoma cruzi. The aim of this work was to analyze histologically and histometrically the sublingual gland of mice infected with the RAL strain of $T$. cruzi, according to the sex. Swiss mice (Mus musculus) were inoculated with $2 \times 10^{4}$ blood trypomastigotes of the RAL strain of T. cruzi. In the peak of the parasitemia (12th day) the mice were sacrificed, and the sublingual glands were fixed in ALFAC. HE-stained histological sections were evaluated histometrically. The parasitemia was higher in females. Histopatologically, acini of the infected animals were smaller, with scanty production of secretion, and smaller striated ducts. The nuclei of the demilunes were smaller and showed amastigote nests in the cytoplasm. Karyometrically, nuclei of the acini, demilunes and striated ducts were smaller in the infected mice. Stereologically, it was observed that relative volumes of acini and ducts were smaller and, inversely, relative volumen were greater for the conjunctive tissue in the infected males. The surface densities of acini and ducts were bigger and the diameter and thickness of the wall were smaller in this group. On the other hand, relative volume of acini was smaller and those of the ducts and conjunctive tissue were bigger in the infected females. The diameter and thickness of the wall of acini were smaller, and those of the striated ducts were bigger in this group. The RAL strain of T. cruzi caused general atrophy in the sublingual gland, with numerous nests of parasites in the glandular parenchyma. Rev. Biol. Trop. 56 (2): 459-471. Epub 2008 June 30.
\end{abstract}

Key words: Trypanosoma cruzi, RAL strain, mouse, sublingual gland, histopathology, histometry.

Chagas y Villela (1922) fueron los primeros que describieron la hipertrofia de las glándulas salivales, especialmente en las parótidas, de pacientes con enfermedad de Chagas portadores de mega-esófago. A pesar de ser la parótida la glándula salival más frecuentemente afectada, muchas veces también se encuentran alteradas las glándulas submaxilar y sublingual (Alvarenga 1934, Meirelles y Losso Neto 1938, Zerbini y Fanganiello 1940, Caldeira 1947, Nash y Morrison 1949, Oliveira et al. 1952, Castro 1953,
Howthorne et al 1956, Mineiro 1958, Câmara et al. 1959, Vieira 1961, Vieira y Handler 1961). El examen histopatológico de las glándulas salivales obtenidas de autopsias de pacientes con enfermedad de Chagas crónica, reveló la existencia de hipertrofia glandular (Caldeira 1947, Nash y Morrison 1949, Oliveira et al. 1952, Vieira y Hadler 1961). Recientemente también fue descripta hipertrofia en las glándulas de von Ebner de pacientes con enfermedad de Chagas crónica (Pereira et al. 2006). 
Las modificaciones provocadas experimentalmente en animales por la infección aguda por el T. cruzi fueron estudiadas histopatologicamente en las glándulas submaxilares (Ribeiro et al. 1977, Alves y Machado 1980, 1984, Martini et al. 1989, Alves et al. 1994, 1995, Lenzi et al. 1996, Borges-Silva y BentoAlves 1996), sublinguales (Ribeiro et al. 1977, Martini et al. 1989, Albuquerque et al. 1992, Alves et al. 1994, Lenzi et al. 1996), parótidas (Ribeiro et al. 1977, Utrilla et al. 1982, 1985, Martini et al. 1986, 1989, 1990a, Lopes et al. 1991a, Lenzi et al. 1996, Silva et al. 2000), de von Ebner (Lopes et al. 1991b) y de Weber (Lopes et al. 1991c).

El estudio histopatológico de las glándulas sublinguales de ratones infectados por las cepas Bolivia o Y de T. cruzi reveló la existencia de atrofia de las estructuras secretorias (Ribeiro et al. 1977). Resultados similares fueron obtenidos en ratas con infección aguda por la cepa Y de T. cruzi por Martini et al. (1989) y Lenzi et al. (1996), mientras que Alves et al. (1994) no observaron ninguna alteración glandular. Albuquerque et al. (1992) demostraron atrofia de los ácinos y alteraciones del parénquima de la sublingual, con presencia de numerosos nidos de parásitos en ratones infectados experimentalmente con las formas anchas de la cepa Bolivia de $T$. cruzi, mientras que los animales infectados con las formas delgadas de esa cepa no sufrieron ninguna alteración glandular.

Los resultados muchas veces contradictorios presentes en los estudios citados se deben a la influencia de varios factores. En primer lugar, existen diversas cepas de T. cruzi que, por sus características biológicas y genéticas, presentan comportamiento peculiar cuando inoculadas en animales de experimentación (Brener 1965). Así, las cepas que muestran predominio de las formas delgadas, presentan curva de parasitemia con pico elevado y precoz, y exhiben tropismo preferencial por células de defensa mono nucleadas, parasitando más frecuentemente los macrófagos del bazo, hígado y médula ósea (Andrade et al. 1970). Las cepas que poseen predominio de las formas gruesas, muestran un marcado tropismo por fibras musculares y tejido glandular (Melo y Brener 1978).

Otro importante factor que puede influir en los resultados es la especie animal utilizada para la inoculación, ya que, además de la existencia de variaciones inter específicas de susceptibilidad a la infección, algunas especies, como ratón, hámster, rata y hurón, pueden presentar dimorfismo sexual de las estructuras de las glándulas salivales (Lacassagne 1940, Raynaud 1960, Dzierzikray-Rogalska et al. 1963, Mudd y White 1975, Di Magioni et al. 1976, Chrétien 1977, Pinkstaff 1980, David et al. 1990, Jezek et al. 1996).

El objetivo del presente trabajo fue evaluar las alteraciones histopatológicas e histométricas de las glándulas sublinguales de ratones machos y hembras, en la fase aguda de la infección provocada por una cepa de $T$. cruzi con marcado tropismo glandular (cepa RAL), correlacionándolas con el sexo de los animales.

\section{MATERIALES Y MÉTODOS}

Usamos 50 ratones blancos (Mus musculus), variedad Swiss (25 machos y 25 hembras), con $20 \mathrm{~g}$ de peso corporal medio. Los animales fueron obtenidos del Bioterio Central del Campus de Ribeirão Preto de la Universidad de Sâo Paulo, y fueron mantenidos en condiciones estandarizadas (ciclo claro/oscuro de 12/12 h, temperatura de $22 \pm 2^{\circ} \mathrm{C}$ y humedad relativa ambiente de $60 \%$ ). Todos los animales fueron alojados en jaulas de polietileno y alimentados con ración comercial y agua ad libitum.

Los ratones fueron divididos en los dos grupos siguientes:

Grupo control, constituido por 20 ratones, 10 machos y 10 hembras, libres de infección.

Grupo infectado, constituido por 30 ratones, 15 machos y 15 hembras, inoculados intraperitonealmente con $2 \times 10^{4}$ formas tripomastigotes sanguíneos de la cepa RAL del T. cruzi. Esta cepa fue aislada del triatomineo Triatoma infestans, proveniente de Santa Rosa de Viterbo, Estado de Sâo Paulo, Brasil (Ribeiro et al. 1993), siendo caracterizada como 
T. cruzi II (Dost et al. 2002). La cepa RAL es mantenida en el Laboratorio de Parasitología de la Facultad de Ciencias Farmacéuticas de Ribeirão Preto por repiques seriados a cada 12 días, mediante inoculación intraperitoneal en ratones blancos, variedad Swiss. La cepa utilizada presenta tripomastigotes con morfología predominantemente gruesa y es patogénica para ratones, mostrando tropismo preferencial por las células glandulares (Albuquerque 1998).

Diez animales inoculados (cinco machos y cinco hembras) fueron empleados para elaborar la curva de parasitemia. Con esa finalidad fueron contados, diariamente, los tripomastigotes presentes en 50 campos microscópicos de sangre retirada de la cola y examinada a 400 aumentos (Brener 1962).

Los restantes 20 ratones infectados (10 machos y 10 hembras) fueron inoculados 20 días después, siendo utilizados para realizar el estudio histopatológico e histométrico de las glándulas sublinguales.

Al $12^{\circ}$ día de infección (pico de la parasitemia), los 20 animales controles y los 20 infectados fueron sacrificados bajo anestesia. Después de la abertura de la piel, las glándulas sublinguales fueron inmediatamente retiradas, separadas de las glándulas submaxilares, y fijadas en solución de ALFAC ( $85 \mathrm{ml}$ de alcohol etílico al $80 \%, 10 \mathrm{ml}$ de formaldehido al $35 \%$ en solución en agua destilada y $5 \mathrm{ml}$ de ácido acético glacial). Después de 24 h de fijación, las glándulas sublinguales fueron incluidas en parafina y los cortes de $6 \mu \mathrm{m}$ de espesor teñidos con hematoxilina y eosina.

Los parámetros nucleares de las células de los ácinos, medialunas serosas y conductos estriados de las glándulas sublinguales fueron estimados para cada grupo (Sala et al. 1994). Con esa finalidad se midieron los ejes mayor (D) y menor (d) de los núcleos en dibujos realizados con auxilio de una cámara clara, determinándose los siguientes parámetros: media geométrica de los diámetros, relación diámetro mayor/diámetro menor, perímetro, área, volumen, relación volumen/área, coeficiente de forma, índice de contorno y excentricidad.
Los parámetros estereológicos, estimados mediante el uso del retículo de Merz (1968), fueron los siguientes: densidad de volumen (Chalkley 1943), densidad de superficie (Tomkeieff 1945), diámetro medio (Sala et al. 1980) y espesor de la pared de las estructuras glandulares (Sala et al. 1981).

Los resultados histométricos obtenidos fueron evaluados estadísticamente mediante análisis de varianza para dos factores de variación-infección y sexo (Sahai y Ageel 2000). Fueron consideradas estadísticamente significativas las diferencias cuando el valor de la "p" fue igual o menor que $5 \%$.

El estudio fue conducido de acuerdo con las exigencias internacionales para uso de animales de laboratorio, siendo el proyecto aprobado por el Comité de Ética en Investigación de la Universidad de Franca (Proc. No. 046/07-A).

\section{RESULTADOS}

Parasitemia: la curva de parasitemia mostró que el pico parasitémico ocurrió al $12^{\circ}$ día de infección, tanto para los ratones machos como para las hembras. Los ratones hembras presentaron mayor concentración de parásitos en la sangre que los machos, diferencia que fue estadísticamente significativa entre el $9^{\circ}$ y el $12^{\circ}$ día de infección $(\mathrm{p}<0.01)$ (Fig. 1)

Histología: las glándulas sublinguales son glándulas ramificadas túbulo-acinosas complejas. Por su secreción, son clasificadas como glándulas mucoserosas mixtas, con predominio de secreción mucosa. Poseen porciones secretorias de los tres tipos: serosas, mucosas y mixtas. Los acinos mixtos, constituidos por medialunas serosas y células mucosas, forman la masa principal de la glándula. Los ácinos serosos, al contrario, son los más escasos.

Al examen histopatológico, las glándulas sublinguales de los ratones machos controles mostraron ácinos mucosos bien constituidos, con células altas y núcleos de forma achatada, situados en la región basal. También fueron observados medialunas serosas y 


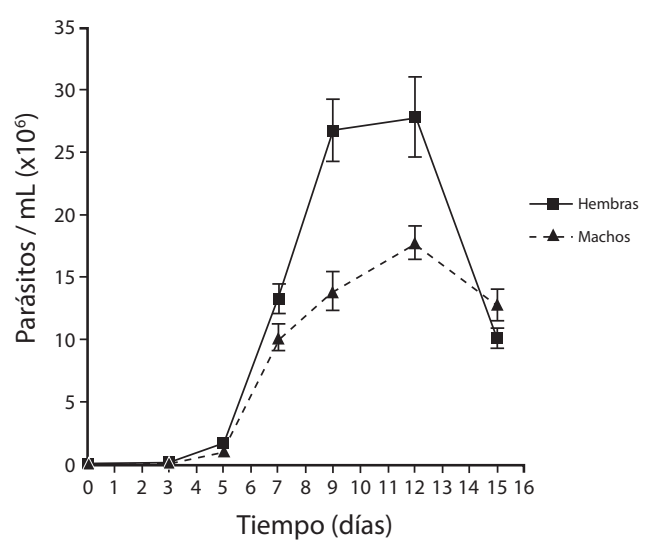

Fig. 1. Curva parasitémica de ratones Swiss machos y hembras infectados con $2 \times 10^{4}$ formas tripomastigotes sanguíneas de la cepa RAL del T. cruzi. $(\mathrm{p}<0,01)$

conductos estriados. Tabiques de tejido conjuntivo dividían la glándula sublingual en lóbulos (Fig. 2).

En los ratones machos infectados por el $T$. cruzi, los ácinos de las glándulas sublinguales poseían escaso producto de secreción, $\mathrm{y}$, al igual que los conductos estriados eran menores que en los machos controles (Fig. 3). Los nidos de amastigotes eran fácilmente visibles en el parénquima glandular (Fig. 3).

El examen histopatológico de las glándulas sublinguales del grupo control de ratones hembras mostró características semejantes a las observadas en las glándulas sublinguales de los machos controles (Fig. 4). Al contrario de lo que ocurre en las otras glándulas salivales mayores o en otros roedores, el dimorfismo sexual en la sublingual de ratón es prácticamente inexistente.

En los ratones hembras infectados, el examen histopatológico permitió observar áreas de desorganización de los ácinos y presencia de parásitos en el parénquima de la glándula sublingual (Fig. 5).

Histometría: el análisis cariométrico de las células de los ácinos, medialunas serosas y conductos estriados de las glándulas sublinguales mostró que la infección por la cepa RAL del T. cruzi causó una reducción estadísticamente

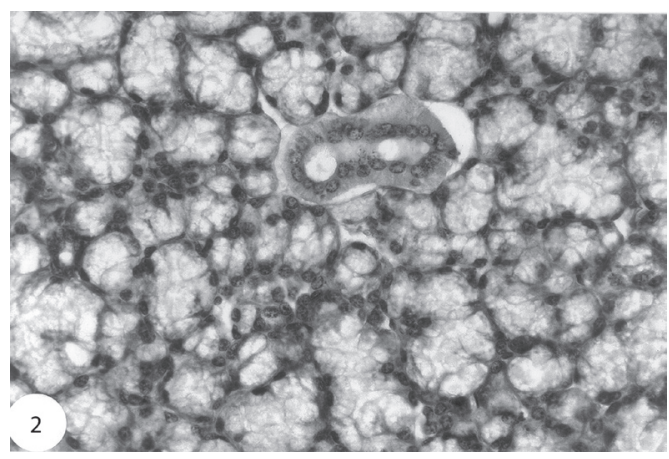

Fig. 2. Glándula sublingual de ratón macho control. Notar ácinos y conductos estriados (HE, x 400).

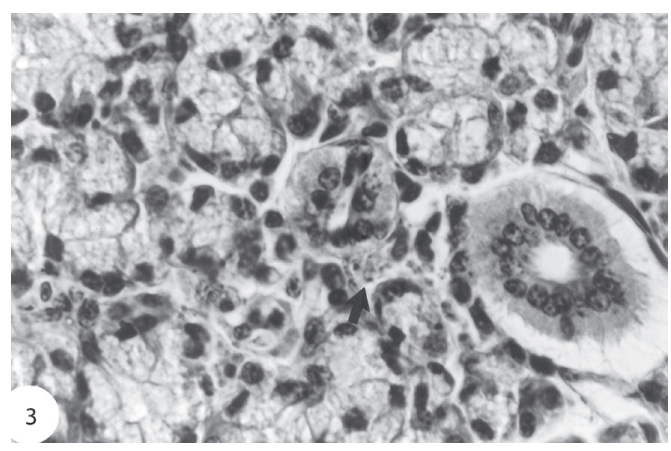

Fig. 3. Glándula sublingual de ratón macho infectado con la cepa RAL del T. cruzi. Notar la desorganización glandular y los nidos de amastigotes (flecha) (HE, x 900).

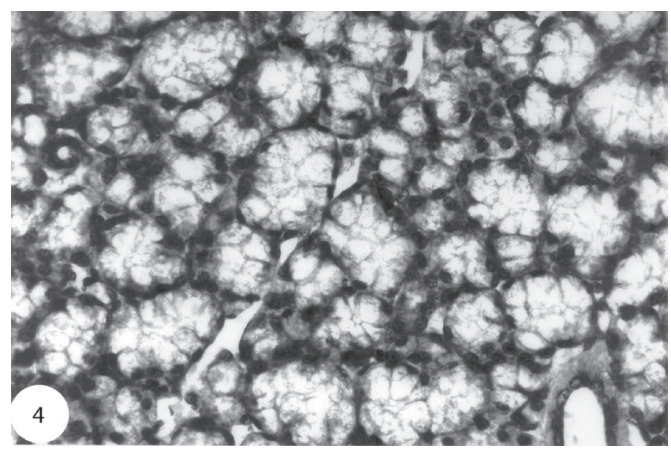

Fig. 4. Glándula sublingual de ratón hembra control. Notar ácinos y conductos estriados (HE, x 400).

significativa del tamaño de los núcleos en todas esas estructuras. La disminución del tamaño nuclear, evaluada por los diámetros, perímetro, área y volumen, ocurrió tanto en los machos $(p<0.01)$ cuanto en las hembras $(p<0.05)$. 


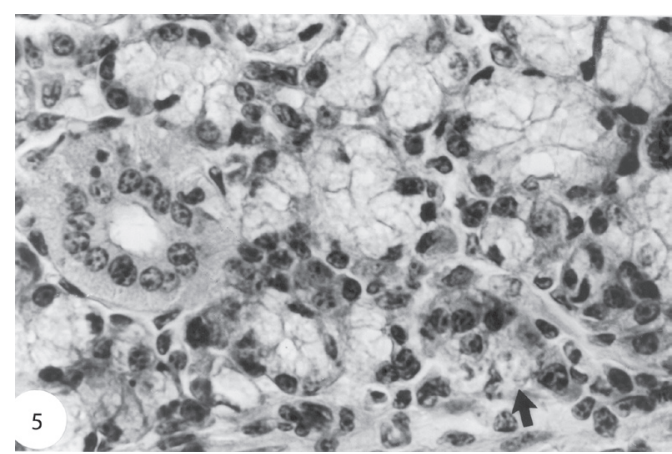

Fig. 5. Glándula sublingual de ratón hembra infectada con la cepa RAL del T. cruzi. Notar los ácinos y conductos con señales de degeneración, además de los nidos de amastigotes (flecha) (HE, x 900).

La forma de los núcleos, evaluada por la relación diámetro mayor/diámetro menor, excentricidad, índice de contorno y coeficiente de forma, no sufrió alteraciones significativas en los animales infectados (Cuadros 1 y 2).

Cuando se compararon los resultados cariométricos entre los ratones controles según el sexo, se demostró que el tamaño nuclear fue significativamente mayor en los ácinos $(\mathrm{p}<0.05)$, medialunas serosas $(\mathrm{p}<0.01)$ y conductos estriados $(\mathrm{p}<0.01)$ de las sublinguales de los machos que en las hembras. La comparación entre los tamaños nucleares en las estructuras glandulares de los animales infectados no mostró diferencias significativas entre machos y hembras.

La forma de los núcleos en los animales infectados presentó diferencia significativa solamente en los ácinos de la sublingual, siendo más redondeados en las hembras que en los machos $(\mathrm{p}<0.05)$. Tanto en las medialunas serosas cuanto en los conductos estriados, los núcleos no mostraron diferencia significativa entre los animales infectados de ambos sexos.

Los resultados estereológicos permitieron observar que los volúmenes relativos ocupados por los ácinos y por los conductos estriados de la glándula sublingual eran significativamente menores en los ratones machos infectados que en los machos controles $(\mathrm{p}<0.01)$. Lo opuesto se observó para el volumen relativo del tejido conjuntivo, que fue significativamente mayor en los machos infectados que en los controles

CUADRO 1

Parámetros nucleares de las células de los “ácinos” y conductos estriados de glándulas sublinguales en ratones.

\begin{tabular}{|c|c|c|c|c|c|c|}
\hline \multirow{2}{*}{ Parâmetro } & \multicolumn{2}{|c|}{ Ácino } & \multicolumn{2}{|c|}{ Medialuna serosa } & \multicolumn{2}{|c|}{ Conducto estriado } \\
\hline & $\mathrm{C}$ & $\mathrm{T}$ & $\mathrm{C}$ & $\mathrm{T}$ & $\mathrm{C}$ & $\mathrm{T}$ \\
\hline Diámetro mayor $(\mu \mathrm{m})$ & $7,68 \pm 0,25$ & $6,55 \pm 0,22 *$ & $6,83 \pm 0,39$ & $5,44 \pm 0,45^{*}$ & $6,38 \pm 0,36$ & $5,09 \pm 0,14^{*}$ \\
\hline Diámetro menor $(\mu \mathrm{m})$ & $3,44 \pm 0,21$ & $2,72 \pm 0,32 *$ & $5,50 \pm 0,34$ & $4,26 \pm 0,28^{*}$ & $5,27 \pm 0,32$ & $3,84 \pm 0,11^{*}$ \\
\hline Diámetro medio $(\mu \mathrm{m})$ & $5,12 \pm 0,24$ & $4,20 \pm 0,29 *$ & $6,12 \pm 0,35$ & $4,80 \pm 0,36^{*}$ & $5,79 \pm 0,33$ & $4,41 \pm 0,10^{*}$ \\
\hline Relación D/d & $2,29 \pm 0,11$ & $2,53 \pm 0,28$ & $1,25 \pm 0,04$ & $1,29 \pm 0,06$ & $1,22 \pm 0,02$ & $1,35 \pm 0,05$ \\
\hline Perímetro $(\mu \mathrm{m})$ & $20,80 \pm 0,73$ & $17,57 \pm 0,68^{*}$ & $19,45 \pm 1,11$ & $15,31 \pm 1,17 *$ & $18,35 \pm 1,06$ & $14,13 \pm 0,33 *$ \\
\hline Área $\left(\mu \mathrm{m}^{2}\right)$ & $20,83 \pm 1,88$ & $14,04 \pm 10,86^{*}$ & $29,66 \pm 3,31$ & $18,36 \pm 2,71 *$ & $26,67 \pm 3,12$ & $15,53 \pm 0,72 *$ \\
\hline Volumen $\left(\mu \mathrm{m}^{3}\right)$ & $49,12 \pm 7,10$ & $22,20 \pm 5,78^{*}$ & $123,28 \pm 20,09$ & $60,28 \pm 13,24 *$ & $105,65 \pm 18,69$ & $47,28 \pm 3,19^{*}$ \\
\hline Relación V/A $(\mu \mathrm{m})$ & $2,30 \pm 0,15$ & $1,82 \pm 0,21^{*}$ & $4,08 \pm 0,23$ & $3,20 \pm 0,24 *$ & $3,86 \pm 0,22$ & $2,94 \pm 0,07 *$ \\
\hline Excentricidad & $0,89 \pm 0,01$ & $0,90 \pm 0,02$ & $0,54 \pm 0,03$ & $0,57 \pm 0,05$ & $0,51 \pm 0,06$ & $0,61 \pm 0,10$ \\
\hline Índice de contorno & $4,59 \pm 0,08$ & $4,75 \pm 0,20$ & $3,59 \pm 0,01$ & $3,60 \pm 0,02$ & $3,58 \pm 0,04$ & $3,62 \pm 0,08$ \\
\hline Coeficiente de forma & $0,60 \pm 0,02$ & $0,57 \pm 0,05$ & $0,98 \pm 0,01$ & $0,97 \pm 0,01$ & $0,98 \pm 0,01$ & $0,96 \pm 0,01$ \\
\hline
\end{tabular}

$* \mathrm{p}<0,01$

Parámetros nucleares (media \pm desviación estándar). Glándulas sublinguales de 10 ratones machos controles (C) y de 10 infectados con la cepa RAL de T. cruzi (T). Análisis de varianza. Resultados correspondientes a la comparación entre controles e infectados. 
CUADRO 2

Parámetros nucleares de células de ácinos y conductos estriados de las glándulas sublinguales de ratones

\begin{tabular}{|c|c|c|c|c|c|c|}
\hline \multirow{2}{*}{ Parámetro } & \multicolumn{2}{|c|}{ Ácino } & \multicolumn{2}{|c|}{ Medialuna serosa } & \multicolumn{2}{|c|}{ Conducto estriado } \\
\hline & $\mathrm{C}$ & $\mathrm{T}$ & $\mathrm{C}$ & $\mathrm{T}$ & $\mathrm{C}$ & $\mathrm{T}$ \\
\hline Diámetro mayor $(\mu \mathrm{m})$ & $6,31 \pm 0,79$ & $5,57 \pm 0,78^{*}$ & $6,17 \pm 0,67$ & $5,33 \pm 0,74^{*}$ & $5,70 \pm 0,79$ & $4,91 \pm 0,72 *$ \\
\hline Diámetro menor $(\mu \mathrm{m})$ & $3,26 \pm 0,59$ & $2,70 \pm 0,48^{*}$ & $4,85 \pm 0,57$ & $4,21 \pm 0,55^{*}$ & $4,52 \pm 0,64$ & $3,74 \pm 0,59^{*}$ \\
\hline Diámetro medio $(\mu \mathrm{m})$ & $4,52 \pm 0,53$ & $3,86 \pm 0,49 * *$ & $5,46 \pm 0,48$ & $4,72 \pm 0,52 * *$ & $5,06 \pm 0,61$ & $4,28 \pm 0,57 * *$ \\
\hline Relación D/d & $1,99 \pm 0,40$ & $2,13 \pm 0,44$ & $1,29 \pm 0,22$ & $1,28 \pm 0,21$ & $1,27 \pm 0,20$ & $1,33 \pm 0,21$ \\
\hline Perímetro $(\mu \mathrm{m})$ & $17,44 \pm 2,00$ & $15,25 \pm 1,97^{*}$ & $14,40 \pm 1,50$ & $15,05 \pm 1,69^{*}$ & $16,13 \pm 1,93$ & $13,68 \pm 1,80 * *$ \\
\hline Área $\left(\mu \mathrm{m}^{2}\right)$ & $16,24 \pm 3,86$ & $11,87 \pm 2,94 *$ & $23,56 \pm 1,50$ & $17,72 \pm 3,93 * *$ & $20,43 \pm 4,87$ & $14,16 \pm 3,82 * *$ \\
\hline Volumen $\left(\mu \mathrm{m}^{3}\right)$ & $36,58 \pm 14,87$ & $22,12 \pm 8,75^{*}$ & $86,99 \pm 22,07$ & $57,11 \pm 19,15^{* *}$ & $70,90 \pm 25,38$ & $43,10 \pm 16,78^{* *}$ \\
\hline Relación V/A ( $\mu \mathrm{m})$ & $2,17 \pm 0,39$ & $1,80 \pm 0,32 *$ & $3,64 \pm 0,32$ & $3,15 \pm 0,35^{* *}$ & $3,38 \pm 0,40$ & $2,85 \pm 0,38^{* *}$ \\
\hline Excentricidad & $0,84 \pm 0,08$ & $0,86 \pm 0,06$ & $0,57 \pm 0,19$ & $0,55 \pm 0,22$ & $0,55 \pm 0,06$ & $0,60 \pm 0,19$ \\
\hline Índice de contorno & $4,37 \pm 0,31$ & $4,47 \pm 0,34$ & $3,60 \pm 0,07$ & $3,60 \pm 0,07$ & $3,60 \pm 0,06$ & $3,61 \pm 0,06$ \\
\hline Coeficiente de forma & $0,67 \pm 0,09$ & $0,64 \pm 0,09$ & $0,97 \pm 0,04$ & $0,97 \pm 0,03$ & $0,97 \pm 0,03$ & $0,97 \pm 0,03$ \\
\hline
\end{tabular}

$* \mathrm{p}<0,05$.

$* * \mathrm{p}<0,01$.

Parámetros nucleares (media \pm desviación estándar); 10 ratones hembras controles (C) y 10 infectados con la cepa RAL de T. cruzi (T). Análisis de varianza. Resultados correspondientes a la comparación entre controles e infectados.

$(\mathrm{p}<0.01)$. En los ácinos y conductos estriados de las sublinguales de los machos infectados, la densidad de superficie era mayor $(\mathrm{p}<0.01)$ y el diámetro y espesor de la pared eran significativamente menores $(p<0.01)$ que en las glándulas de los machos controles.

En las sublinguales de las hembras, la densidad de volumen de los ácinos era menor $(\mathrm{p}<0.01)$ y la de los conductos estriados y tejido conjuntivo era mayor en las infectadas que en las controles $(p<0.01)$. Las densidades de superficie de los ácinos, conductos estriados y tejido conjuntivo de las glándulas sublinguales eran mayores en las hembras infectadas que en las hembras controles. El diámetro y espesor de las paredes de los ácinos eran menores $(\mathrm{p}<0.01)$, mientras que el diámetro y espesor de las paredes de los conductos estriados eran mayores $(\mathrm{p}<0.05)$ en las glándulas sublinguales de las hembras infectadas que en las glándulas de las hembras controles (Cuadro 3).
Cuando se realizó la comparación entre los ratones controles de ambos sexos, solamente existió diferencia significativa en el diámetro medio de los ácinos de las glándulas sublinguales, que fue significativamente menor en las hembras que en los machos $(\mathrm{p}<0.01)$. La comparación entre los parámetros estereológicos correspondientes a las glándulas sublinguales de los ratones infectados, según el sexo, permitió observar la existencia de un aumento significativo del volumen relativo y de la densidad de superficie de los ácinos en las sublinguales de los machos $(\mathrm{p}<0.01)$. No hubo diferencias significativas entre los volúmenes relativos del tejido conjuntivo, diámetro medio de los ácinos y espesor medio de la pared de los ácinos de las sublinguales pertenecientes a los machos y hembras infestados. El volumen relativo, el diámetro medio y el espesor de la pared de los conductos estriados fueron significativamente mayores en las sublinguales 


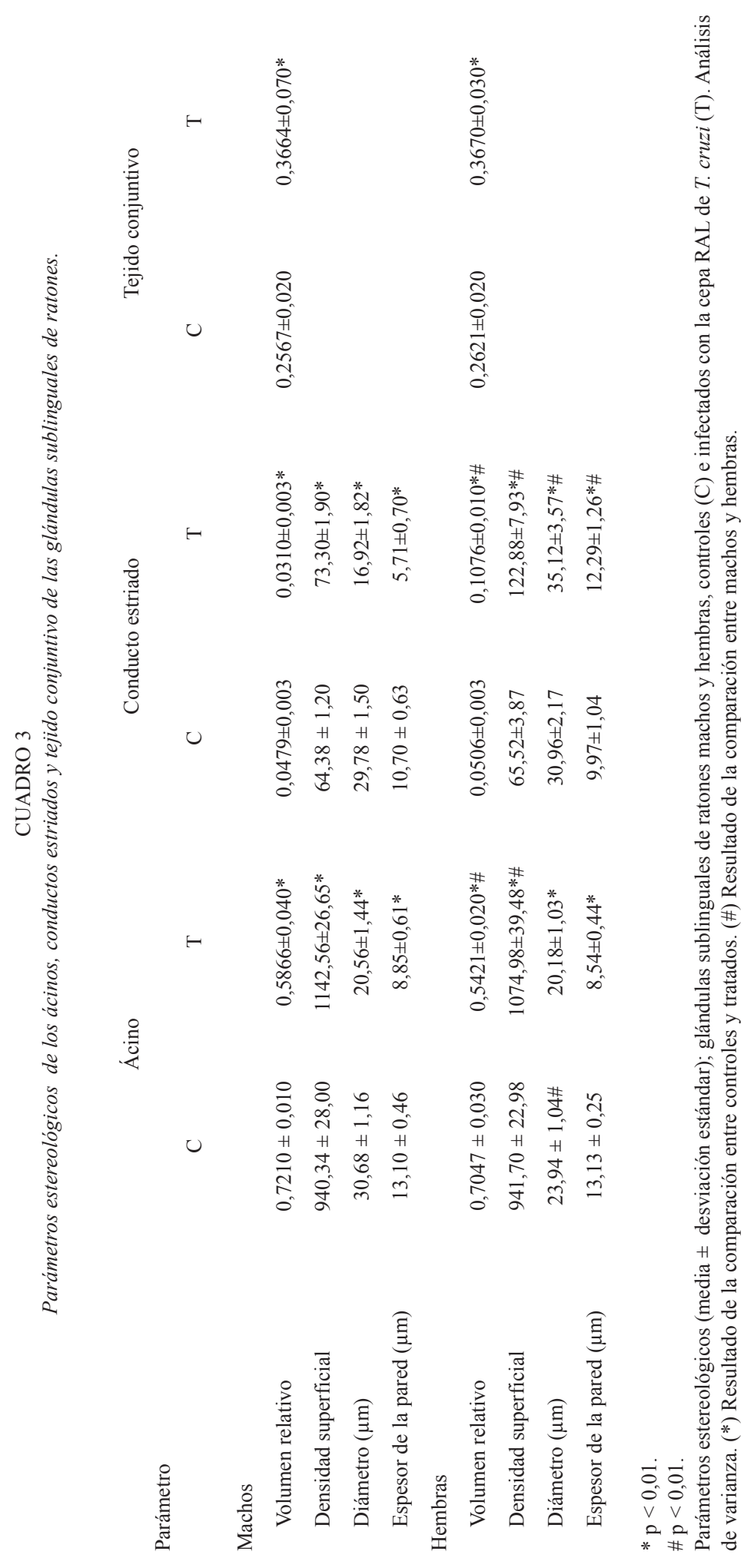


de las hembras infectadas que en los machos infectados $(\mathrm{p}<0.01)$. Al contrario, la densidad de superficie de los conductos estriados de las glándulas sublinguales fue significativamente menor en los ratones hembras infectados que en los machos infectados $(\mathrm{p}<0.01)$.

\section{DISCUSIÓN}

Hauschka (1947) demostró que las hormonas sexuales eran factores importantes en la variación entre los sexos, mostrada por la infección provocada por el T. cruzi. Kagan y Norman (1960), al contrario, no observaron diferencias de susceptibilidad entre ratones CFW machos y hembras infectados. Mientras tanto, estos resultados deben ser vistos con cautela, ya que el número de parásitos inoculados era variable, así como la edad y el peso de los animales infectados, siendo el número de ratones machos mucho mayor que el de hembras. Chapman et al. (1975) observaron mayor susceptibilidad de los ratones CF-1 machos a infecciones agudas por T. cruzi, mientras que Hoff et al. (1979) no hallaron diferencias relacionadas al sexo en la parasitemia de ratones infectados por el tripanosoma. En el presente trabajo se demostró que los ratones hembras infectados por la cepa RAL del T. cruzi presentaron mayor índice de parasitemia que los ratones machos, permitiendo suponer que ese resultado, además de estar relacionado a las hormonas gonadales femeninas, puede ser dependiente de las características biológicas de la cepa utilizada.

La patogenia del T. cruzi es determinada por las características del huésped y de la población infectante del parásito. Así, el curso de la infección en las especies susceptibles puede ser influenciado por factores como temperatura ambiente, edad, sexo, constitución genética del hospedero y características genéticas y morfológicas de la cepa infectante (Brener et al. 2000). Varios trabajos han evidenciado que las cepas de T. cruzi constituyen poblaciones complejas que difieren por sus características morfológicas, biológicas y genéticas, así como por el desarrollo y comportamiento de la infección en el huésped (Brener et al. 2000).

La presencia de tripanosomas es raramente observada en las glándulas salivales, aún cuando son utilizadas especies diferentes y cepas diversas de $T$. cruzi. Nidos de amastigotes fueron descritos con mayor frecuencia en el estroma de las glándulas salivales en ratones inoculados con la cepa Chinga, proveniente de Costa Rica (Bice y Zeledón 1970) y con las cepas Y y CL, provenientes de Brasil (Gonçalves da Costa et al. 1986).

Marsden y Hagstrom (1966) describieron la existencia de seudoquistes en las glándulas salivales de perros inoculados con una cepa peruana de $T$. cruzi, sugiriendo la posibilidad de que los nidos de amastigotes situados muy próximos de los conductos salivales podrían permitir el pasaje de tripomastigotes para la saliva. Este hecho fue observado experimentalmente por Martini et al. (1989), que verificaron la presencia de amastigotes en el interior de la luz de los conductos de glándulas salivales de ratones infectados por la cepa Bolivia de $T$. cruzi. Los resultados de este trabajo sugieren que los parásitos, presentes en el parénquima, puedan alcanzar el sistema de conductos de las glándulas salivales y que, probablemente, el $T$. cruzi puede ser transportado por la saliva.

Las mayores alteraciones de las glándulas salivales fueron registradas en la parótida. Los pacientes portadores de la enfermedad de Chagas crónica, con mega esófago, presentan, generalmente, aumento del volumen de esa glándula. Los exámenes histopatológicos confirmaron la existencia de hipertrofia glandular (Caldeira 1947, Nash y Morrison 1949, Oliveira et al. 1952, Vieira y Hadler 1961). Estas alteraciones glandulares fueron atribuidas a la destrucción de neuronas y alteraciones de los ganglios autónomos, causando inhibición de los movimientos peristálticos del esófago y provocando disfagia (Dantas 1998). Los estímulos mecánicos determinados por la masticación y por el impedimento o la dificultad de libre pasaje del bolo alimentar en el esófago en esos pacientes, causa un aumento en la producción de saliva (sialorrea), con 
la consecuente hipertrofia glandular (Correia Neto 1935, Vieira y Hadler 1961, Cunha et al. 2005).

Al contrario, la mayoría de las investigaciones experimentales han demostrado la existencia de atrofia de las glándulas salivales en la fase aguda de la infección. El examen histopatológico reveló atrofia de los ácinos de las diversas glándulas salivales en ratas y ratones (Ribeiro et al. 1977, Utrilla et al. 1982, 1985, Martini et al. 1986, 1989, 1990a, Lopes et al. 1991a, 1991b, 1991c, Albuquerque et al. 1992, Borges-Silva y Bento-Alves 1996, Lenzi et al. 1996, Silva et al. 2000).

En el presente estudio se observó un cuadro general de atrofia de la glándula sublingual en los ratones inoculados con la cepa RAL de T. cruzi. También fue descrita atrofia de la glándula sublingual en ratones inoculados con las cepas Bolivia o Y del T. cruzi (Ribeiro et al. 1977, Martíni et al. 1989). Mientras tanto, en ratas infectadas con la cepa Y de T. cruzi, Alves et al. (1994) no observaron ninguna alteración glandular. Albuquerque et al. (1992) estudiaron los efectos de dos submuestras (formas delgadas y formas gruesas) de la cepa Bolivia del $T$. cruzi, y demostraron que la submuestra de formas gruesas provocó alteraciones semejantes a las provocadas por la cepa original, mientras que la submuestra de formas delgadas no causó ninguna modificación glandular.

En el presente trabajo fueron señaladas alteraciones de las glándulas sublinguales que afectan de manera diferente a los ácinos y a los conductos estriados, de acuerdo con el sexo del animal inoculado. En primer lugar, las alteraciones que ocurren en los ácinos de la glándula sublingual, caracterizadas por atrofia, son independientes del sexo del ratón. La atrofia acinar puede ser causada por la alteración de la inervación simpática y parasimpática (Hillarp 1949). La infección por el T. cruzi podría provocar la destrucción o alteración de la inervación de la glándula sublingual, siendo responsable por la atrofia observada. Otro posible mecanismo, indirecto, puede ser desencadenado por las alteraciones pancreáticas debidas a la infección por T. cruzi (Martini et al. 1990b), que causan disminución de la síntesis y secreción de insulina. En este sentido, es necesario frisar que la única hormona que parece tener influencia sobre las glándulas sublinguales es la insulina, al contrario de lo que ocurre con las otras glándulas salivales mayores (Shafer y Muhler 1953, Baker y Abrams 1955, Baker et al. 1964). Fue demostrado que esa hormona actúa sobre la glándula sublingual, manteniendo su integridad morfológica y funcional (Petenusci et al. 1979), de manera que las alteraciones pancreáticas provocadas por el T. cruzi podrían afectar, indirectamente, las características morfo funcionales de las glándulas sublinguales.

Con relación a los conductos estriados de las glándulas sublinguales, se observó un comportamiento diferente ante la infección por el T. cruzi, según el sexo de los ratones, atrofia en los machos e hipertrofia en las hembras. Al contrario de lo que ocurre en las otras glándulas salivales mayores de los ratones, la sublingual no presenta dimorfismo sexual evidente. Mientras tanto, mediante métodos bioquímicos e histoquímicos, fueron demostradas diferencias entre los conductos estriados de las glándulas sublinguales de los ratones machos y hembras (Spicer 1961). En este sentido, el comportamiento diferente de los conductos estriados en las glándulas sublinguales de los ratones según el sexo, puede estar relacionado a una respuesta metabólica disímil a la infección $\mathrm{o}$, aún, a la disminución del estímulo que la insulina ejerce normalmente sobre esas glándulas (Liu y Lin 1969, Petenusci et al. 1979).

Concluyendo, es posible afirmar que la cepa RAL del $T$. cruzi provoca en la glándula sublingual de ratones de ambos sexos, un cuadro general de atrofia con la demostración de numerosos nidos de parásitos en el parénquima glandular.

\section{RESUMEN}

Analizamos morfológica e histométricamente la glándula sublingual de ratones infectados con la cepa RAL del Trypanosoma cruzi, en machos y hembras. Usamos ratones albinos (Mus musculus), variedad Swiss, 
inoculados con $2 \times 10^{4}$ tripomastigotes sanguíneos de la cepa RAL del T. cruzi.. Sacrificamos los animales en el pico de la parasitemia $\left(12^{\circ}\right.$ día $)$ y fijamos las glándulas sublinguales en ALFAC. Los cortes histológicos teñidos con $\mathrm{HE}$ fueron evaluados histométricamente (cariometría y estereología). La parasitemia fue más elevada en las hembras. Histopatológicamente, los "ácinos" (acini) de los animales infectados eran menores, con escasa secreción, y conductos estriados menores. Los núcleos de las "medialunas" eran menores y había nidos de amastigotes en el citoplasma. Cariométricamente, los núcleos de los ácinos, medialunas y conductos estriados eran menores en los ratones infectados. Estereológicamente, los volúmenes relativos ocupados por ácinos y conductos estriados fueron menores e, inversamente, fue mayor el volumen para el tejido conjuntivo de los machos infectados. Las densidades de superficie de ácinos y conductos fueron mayores, y el diámetro y el espesor de la pared menores, en este grupo. Por otro lado, la densidad de ácinos fue menor, y las de los conductos estriados y tejido conjuntivo, fueron mayores en las hembras infectadas. Las densidades de superficie de ácinos y conductos estriados fueron mayores, mientras que el diámetro y espesor de la pared de los ácinos fueron menores (y las de los conductos estriados mayores), en este grupo. La cepa RAL del T. cruzi causó un cuadro general de atrofia general en la glándula sublingual, con numerosos nidos de parásitos.

Palabras clave: Trypanosoma cruzi, cepa RAL, ratón, glándula sublingual, histopatología, histometría.

\section{REFERENCIAS}

Albuquerque, S. 1998. Estudo morfológico, morfométrico e estereológico das alterações presentes nas glândulas salivares maiores e acessórias do camundongo infectado pelo Trypanosoma cruzi. Tese de Doutorado, Universidade de Campinas, Campinas, São Paulo, Brasil.

Albuquerque, S., R.A. Lopes, R.D. Ribeiro, T.L.L. Carvalho, M.C. Komesu \& A.A. Carraro. 1992. Alterações da glândula submandibular de camundongos infectados com formas polimórficas da cepa Bolívia do Trypanosoma cruzi. An. Farm. Quim. 31/32: 68 .

Alvarenga, A.M. 1934. Cardiospasmo (Mal de engasgo). Imprensa do Estado, Belo Horizonte, Minas Gerais, Brasil.

Alves, J.B. \& C.R.S. Machado. 1980. Histopathological and histoquantitative study of the rat submandibular gland in Chagas disease. Arch. Oral Biol. 25: 437-443.
Alves, J.B. \& C.R.S. Machado. 1984. Changes in acetylcholinesterase positive nerves of the submandibular salivary gland during experimental infection with a protozoon, T. cruzi in rats. Arch. Oral Biol. 29: 647-651.

Alves, J.B., M.C. Ulrich-Karine \& M.S.D. Alves. 1995. Morphology of rat submandibular gland acinar secretory granules and their alteration during the acute phase of experimental Chagas' disease. Braz. J. Med. Biol. Res. 28: 761-766.

Alves, J.B., M.S. Alves \& R.C.P. Reis. 1994. Histological and histometric study of the rat sublingual gland in the acute phase of experimental Chagas disease. Rev. Bras. Cienc. Morfol. 11: 39-44.

Andrade, S.G., M.L. Carvalho \& R.M. Figueira. 1970. Caracterização morfobiológica e histopatológica de diferentes cepas de Trypanosoma cruzi. Gaz. Med. Bahia. 70: 32-42.

Baker, B.L. \& G.D. Abrams. 1955. Growth hormone (somatotropin) and the glands of the digestive system, p. 107-122. In H.W. Clapp Jr., U.H. Gaebler \& C.N.H. Long (eds.). The hypophyseal growth hormone. Nature and action. Blakiston Div, Mc Graw Hill, Nueva York, EEUU.

Baker, B.L., H.W. Clapp Jr. \& J.A. Light. 1964. Hormonal influences on the cytology and physiology of salivary glands. Int. Ser. Oral Biol. 3: 63-81.

Bice, D.E. \& R. Zeledón. 1970. Comparison of infectivity of strains of Trypanosoma cruzi (Chagas, 1909). J. Parasitol. 56: 663-670.

Borges-Silva, G.A. \& J. Bento-Alves. 1996. Morphological analysis of an isolated fraction containing secretory granules from the submandibular gland of Trypanosoma cruzi infected and normal rats. Biotech. Histochem. 71: 207-209.

Brener, Z. 1962. Therapeutic activity and criterion of cure in mice experimentally infected with Trypanosoma cruzi. Rev. Inst. Med. Trop. São Paulo 4: 220-224.

Brener, Z. 1965. Comparative studies of different strains of Trypanosoma cruzi. Ann. Trop. Med. Parasitol. 59: $19-26$.

Brener, Z., Z.A. Andrade \& M. Barral-Netto. 2000. Trypanosoma cruzi e doença de Chagas, p. 177-200. In Z. Brener, Z.A. Andrade \& M. Barral-Netto (eds.). Patologia experimental da doença de Chagas, Guanabara Koogan, Rio de Janeiro, Brasil.

Caldeira, O.V. 1947. Arriboflavinose. Queiroz Breiner, Belo Horizonte, Minas Gerais, Brasil. 
Câmara, J., L. Paiva \& F. Freire. 1959. Valor da sialografia funcional. Rev. Hosp. Clin. 14: 1-10.

Castro, F.P. 1953. Alguns aspectos do diagnostico e do tratamento do megaesôfago por acalásia do cárdia. Arq. Bras. Med. 43: 351-362.

Chagas, C. \& E.A. Villela. 1922. Forma cardíaca da trypanosomiase americana. Mem. Inst. Oswaldo Cruz 14: 3-61.

Chalkey, H.W. 1943. A method for the quantitative morphologic analysis of tissues. J. Nat. Cancer Inst. 4: 47-53.

Chapman, J.R., W.L. Hanson \& V.B. Waits. 1975. The influence of gonadectomy of host on parasitemia and mortality of mice infected with Trypanosoma cruzi. J. Parasitol. 61: 213-216.

Chrétien, M. 1977. Action of testosterone on differentiation and secretory activity of a target organ: the submandibullary gland of the mouse. Int. Rev. Cytol. 50: 333-396.

Correia Neto, A. 1935. Patogenia, diagnóstico e tratamento do megaesôfago (mal de engasgo). Editora Nacional, San Pablo, San Pablo, Brasil.

Cunha, D.A., H.J. Silva, S.R.A. Moraes \& T. Tashiro. 2005. Prevalência de alterações no sistema estomatognático em portadores da doença de Chagas. Rev CEFAC 7: 215-220

Dantas, R.O. 1998. Dysphagia in patients with Chagas' disease. Dysphagia 13: 53-57.

David, M.L.R., A. Cáceres \& A. Goldraij. 1990. Dimorfismo sexual en la glándula submaxilar de la rata. Acta Odont. Latinoam. 5: 63-69.

Di Magioni, C., S. Stefano, M. Ruggiero \& M. Brunese. 1976. Inhibition of labeled testosterone in the rat parotid gland with natural and synthetic anti-androgens. Boll. Soc. Ital. Biol. Sper. 52: 411-417.

Dost, C., S. Albuquerque, V. Hemleben, W. Engels \& J. Prado. 2002. Molecular genetics characterization of different Trypanosoma cruzi strains and comparison of their development in Mus musculus and Calomys callosus. Parasitol. Res. 88: 609-616.

Dzierzikray-Rogalska, I., S. Chodynicki \& L. Wisniewski. 1963. The effect of gonadectomy on the parotid gland and Leventhal's gland in white mice. Acta Med. Pol. 4: $221-228$

Gonçalves da Costa, S.C., K.S. Calabrese, A. Alencar \& P.H. Lagrange, 1986. Trypanosoma cruzi invasion of structures related to development and central nervous system. Rev. Bras. Neurol. 22: 183-190.

Hauschka, T.S. 1947. Sex of host as a factor in Chagas' disease. J. Parasitol. 33: 339-404.

Hillarp, N. 1949. Critical remarks on the problem of double innervation of the salivary glands. Acta Anat. 8: $190-200$

Hoff, R., K.E. Mott, J.F. Silva, V. Menezes, J.N. Hoff, T.V. Barrnett \& I. Sherlock. 1979. Prevalence of parasitemia and seroreactivity to Trypanosoma cruzi in a rural population of Northeast Brazil. Amer. J. Trop. Med. Hyg. 72: 247-250.

Howthorne, H.R., A.S. Frobese \& P. Nemir. 1956. The surgical menagement of achalasia of the esophagus. Ann. Surg. 144: 653-666.

Jezek, D., L. Banek \& T. Banek. 1996. Effect of orchiectomy on the rat parotid gland. An ultrastructural and stereological study. Acta Anat. 155: 172-183.

Kagan, I.G. \& L. Norman. 1960. Immunologic studies on Trypanosoma cruzi. Susceptibility of CPW stock mice for the "Tulahuen" strain of T. cruzi. J. Infect. Dis. 107: 165-167.

Lacassagne, A. 1940. Dimorphisme sexuel de la glande sous-maxillaire chez la souris. C.R. Soc. Biol. (Paris) 133: $180-182$.

Lenzi, H.L., D.N. Oliveira, M.T. Lima \& C.R. Gattass. 1996. Trypanosoma cruzi paninfectivity of CL strain during murine acute infection. Exper. Parasitol. 84: 16-27.

Liu, F.T. \& H.S. Lin. 1969. Role of insuline in body growth and the growth of salivary and endocrine glands in rats. J. Dental Res. 48: 557-567.

Lopes, R.A., R.D. Ribeiro, T.L.L. Carvalho, S. Albuquerque \& I. Watanabe. 1991c. Presence of amastigotes in the Weber's lingual salivary glands of Trypanosoma cruzi-infected mice. Braz. Dental J. 2: 75-79.

Lopes, R.A., R.D. Ribeiro, T.L.L. Carvalho, S. Albuquerque \& I. Watanabe. 1991b. Histopathological study of Von Ebner's lingual salivary glands in Trypanosoma cruzi-infected mice. Angew. Parasitol. 32: 75-78.

Lopes, R.A., T.L.L. Carvalho, R.D. Ribeiro, S. Albuquerque \& I. Watanabe. 1991a. Tropismo tissular de diferentes cepas do Trypanosoma cruzi. V. Estudo histopatológico das alterações da glândula parótida de camundongos infectados com a cepa RC. Rev. Esc. Farm. Odont. Alfenas 13: 83-89. 
Marsden, P.D. \& J.W.C. Hagstrom. 1966. Trypanosoma cruzi in the saliva of beagle puppies. Trans. Royal Soc. Med. Hyg. 60: 189-191.

Martini, A.S., R.A. Lopes, L.S. Utrilla, R.D. Ribeiro \& C.C.A. Reis. 1986. Morphological and morphometric study of the alterations on young mouse parotid gland with subpatent Chagas' disease. Angew. Parasitol. 27: 65-72.

Martini, A.S., R.A. Lopes, R.D. Ribeiro, L.S. Utrilla \& C.C.A. Reis. 1989. Histopathological study of the major salivary glands in Trypanosoma cruzi -infected mice. Ann. Parasitol. Hum. Comp. 64: 512-515.

Martini, A.S., C.C.A. Reis, L.S. Utrilla, R.D. Ribeiro \& R.A. Lopes. 1990a. Morphologic and morphometric study of changes in the mouse parotid gland in the acute phase of Chagas' disease. Rev. Odont. Univ. São Paulo 4: 284-288.

Martini, A.S., L.S. Utrilla, C.C.A. Reis, R.D. Ribeiro \& R.A. Lopes. 1990b. Estudo morfológico e morfométrico das alteraçöes pancreáticas de camundongos na fase aguda da doença de Chagas. Rev. Ciênc. Farm. 12: 131-139.

Meirelles, N. \& A. Losso Netto. 1938. Contribuição ao estudo do megaesôfago. Hospital 14: 979-985.

Melo, R.C. \& Z. Brener. 1978. Tissue tropism of different Trypanosoma cruzi strains. J. Parasitol. 64: 475-482.

Merz, W.A. 1968. Die Streckenmessung an gerichteten Strukturen im Mikroskop und ihre anwendung zur Bestimmung von Oberflächen-Volumen-relationen im Knochengewebe. Mikroskopie 22: 132-142.

Mineiro, V. 1958. Contribuição à etiologia do megaesôfago. Distribuição geográfica. Rev. Goiana Med. 4: 29-34.

Mudd, B.D. \& S.C. White. 1975. Sexual dimorphism in the rat submandibular gland. J. Dental Res. 54: 193.

Nash, L. \& L.G. Morrison. 1949. Asymptomatic chronic enlargement of the parotid glands. Ann. Oto. Rhino. Laring. 58: 646-665.

Oliveira, H.L., W. Bloise \& A.G. Lopes. 1952. Hiperatividade de glândulas salivares como causa da hiperamilasemia verificada em caso de megaosôfago. Possível valor semiológico da relação amilasemia/ lipasemia. Rev. Paul. Méd. 41: 238-245.

Pereira, S.A.L., D.B.R. Rodrigues, M.L.F. Ferraz, E.C.C. Castro, M.A. Reis \& V.P.A. Teixeira. 2006. Inflammation and glandular duct dilatation of the tongue from patients with chronic Chagas disease. Parasitol. Res. 98: 153-156.

Petenusci, S.O., R.A. Lopes \& C.R. Silva Netto. 1979. Estudo morfométrico dos efeitos da insulina na glândula sublingual do rato. Rev. Fac. Farm. Odont. Ribeirão Preto 16: 47-52.

Pinkstaff, C.A. 1980. Sexual dimorphism of the sublingual glands in tree shrews. Basic Appl. Histochem. 24: 95-100.

Raynaud, J. 1960. Controle hormonal de la glande sousmaxillaire de la souris. Bull. Biol. Fr. Belg. 94: 339-523.

Ribeiro, R.D., R.A. Lopes, S.O. Petenusci, G. Maia Campos \& N.C. Petenusci. 1977. Alterações de glândulas salivares de camundongos e ratos infectados pelo Trypanosoma cruzi. Rev. Fac. Farm. Odont. Ribeirão Preto 14: 35-40.

Ribeiro, R.D., S. Albuquerque, A.A. Carraro, R.A. Lopes, J.C. Prado Jr, T.A.R. Garcia \& M.P.A. Toldo. 1993. Uma nova cepa do Trypanosoma cruzi isolada do triatomíneo Triatoma infestans. Anais da Reunião Anual da SBPC 45: 769-770.

Sahai, H. \& M.I. Ageel. 2000. The analysis of variance. Birkhäuser, Boston, Massachusetts, EEUU.

Sala, M.A., M. Matheus \& V. Valeri. 1980. A stereological method for estimating average diameter on spheric structures. Rev. Pesq. Med. Biol. 13: 157-158.

Sala, M.A., M. Matheus \& V. Valeri. 1981. A new stereological method for estimating the thickness of a cellular layer on random sections. Mikroskopie 38: 127-130.

Sala, M.A., M.C. Komesu, R.A. Lopes \& G. Maia Campos. 1994. Karyometric study of basal cell carcinoma. Braz. Dental J. 5: 127-130.

Shafer, W.G. \& J.C. Muhler. 1953. Effect of gonadectomy and sex hormones on the structure of the rat salivary gland. J. Dental Res. 32: 262-268.

Silva, R.C., J.E. Cardoso, G.A.B. Silva, A. Moreira \& J.B. Alves. 2000. Histological and histoquantitative study of the rat parotid gland after Trypanosoma cruzi infection. Parasite 7: 109-113.

Spicer, S.S. 1961. The use of various cationic reagents in histochemical differentiation of mucopolyssacharides. Am. J. Clin. Pathol. 36: 393-407. 
Tomkeieff, S.I. 1945. Linear intercepts areas and volumes. Nature 155: 24.

Utrilla, L.S., A.S. Martini, R.D. Ribeiro \& Y. Sabbag. 1982. Sialoadenopatia chagásica: estudo experimental da glândula parótida. Rev. Ciênc. Farm. 4: 21-25.

Utrilla, L.S., R.A. Lopes, R.D. Ribeiro, C.C.A. Reis \& A.S. Martini. 1985. Alterações histoquímicas da glândula parótida de camundongos na fase subpatente da doença de Chagas. Rev. Fac. Odont. Ribeirão Preto 22: 7-10.
Vieira, C.B. \& W.A. Hadler. 1961. Estudo histológico da glândula parótida e do pâncreas no megaesôfago. Rev. Assoc. Med. Brasil. 7: 89-96.

Vieira, C.B. 1961. Hyperamylasemia and hyperactivity of salivary glands associated with megaesophagus. Am. J. Dig. Dis. 6: 727-741.

Zerbini, E.J. \& A. Fanganiello. 1940. Sialoangiografia da parótida. Rev. Cir. São Paulo 6: 159-195. 